\title{
Valor nutritivo dos alimentos utilizados na formulação de rações para peixes tropicais
}

\author{
Luiz Edivaldo Pezzato1, Margarida Maria Barros'1, Wilson Massamitu Furuya ${ }^{2}$ \\ ${ }^{1}$ Unesp - Universidade Estadual Paulista - FMVZ - Botucatu - São Paulo, CEP: 18618-000, CP: 560 \\ 2 UEM - Universidade Estadual de Maringá - Maringá - PR, CEP: 87020-900.
}

RESUMO - A seleção de ingredientes para a formulação de dietas para peixes requer o conhecimento prévio dos coeficientes de digestibilidade aparente da energia e nutrientes. O valor nutritivo de vários alimentos tem sido investigado no Brasil e o uso de fontes alternativas não deve resultar em efeitos negativos sobre o desempenho, saúde dos peixes e qualidade da água. Diversos fatores podem afetar a digestibilidade, sendo que os coeficientes de digestibilidade aparente dos ingredientes devem ser utilizados para a formulação de rações mais precisas e econômicas.

Palavras-chave: digestibilidade, ingredientes, nutrição, peixe

\section{Nutritive value of common feeds used in tropical fish diets}

\begin{abstract}
Selection of potential ingredients for feed formulation for any fish species requires knowledge of the apparent digestibility coefficients of energy and nutrients. The nutritive value of various ingredients has been investigated in Brazil and alternative source is must support similar fish performance and no adverse effects on fish health and the environment. Several factors can affect nutrient digestibility and the apparent digestibility coefficients of wide range of feed ingredients should be used for more accurate and economical feed formulation.
\end{abstract}

Key Words: digestibility, fish, ingredients, nutrition

\section{Introdução}

A criação de peixes constitui uma das áreas da produção animal que mais se desenvolve no Brasil. Para atender a expansão desta indústria e da demanda do mercado, as técnicas de produção se mostram ainda mais intensivas.

Pesquisas têm sido desenvolvidas para a obtenção de informações necessárias para a formulação de rações que atendam as exigências das espécies de peixes cultivadas. Apenas o alimento balançado permite a máxima resposta produtiva e referente às espécies de peixes tropicais, faltam informações de suas necessidades nutricionais e do valor nutritivo dos alimentos que compõem suas dietas. Além disso, algumas das recomendações se baseiam em investigações realizadas em condições climáticas muito diferentes das nossas.

Para proporcionar saúde aos peixes confinados e minimizar impactos ambientais, é fundamental que se obtenham maiores informações do valor nutritivo dos alimentos e das necessidades nutricionais dessas espécies de peixes, as quais permitam balancear rações para diferentes fases da vida. Em função do sistema intensivo de cultivo, tem-se procurado nutrir os peixes de forma que suportem o rápido crescimento e o estresse a que estão constantemente expostos, minimizando desta forma as possíveis perdas.

Sabe-se que a digestibilidade e a disponibilidade de nutrientes permitem o balanço da dieta. Isso influencia o equilíbrio orgânico animal, determina maior resistência a doenças e responde por maior produtividade em sistemas intensivos. Desta forma, deve-se questionar o valor nutritivo dos alimentos que compõem as rações utilizadas nos sistemas intensivos de produção, visando a confecção de rações balanceadas de alta qualidade, para a aplicação de boas práticas de manejo.

\section{Alimentos concentrados}

A produção mundial de farinha de peixe não atende a quantidade necessária para confecção das rações para os organismos aquáticos. O preço da farinha de peixe tem aumentado como resultado da aceleração da demanda mundial e, em conseqüência, os alimentos concentrados protéicos de origem vegetal se mostram como opção. As 
rações de peixes e camarões marinhos consomem aproximadamente $50 \%$ da farinha de peixe disponível no mercado mundial, sendo provável que a quantidade de ração balanceada necessária para alimentar essas espécies duplique em dez anos.

O crescimento maior da demanda que da produção resulta em elevação dos preços dos produtos envolvidos. Em conseqüência, os cereais (base energética da fórmula) e os demais alimentos protéicos, inclusive aqueles de origem vegetal (co-produtos e subprodutos das oleaginosas) também são significativamente valorizados.

A relação energia/proteína se mostra como a base do balanceamento da ração e a proteína dietária (balanço aminoácidico) representa cerca de $60 \%$ do custo da ração. Qualquer que seja o alimento protéico (animal ou vegetal) utilizado na formulação, o preço desse balanço não pode ser alterado com facilidade. Pior ainda, substituições não engenhosas podem proporcionar perdas substanciais ao desempenho e a saúde dos animais e, ao ambiente.

A obtenção da mais adequada relação energia/ proteína para uma determinada espécie, depende principalmente do valor nutritivo dos alimentos combinados. A indústria de ração paga pelos valores digestíveis dos alimentos presentes no mercado. Assim, o aporte nutritivo é o que determina os preços dos alimentos energéticos como milho, trigo, arroz ou do sorgo e, dos protéicos como as farinhas de peixe ou de carne e os farelos de soja, canóla ou algodão.

Teoricamente, a ração é composta por alimentos protéicos e energéticos, os quais se apresentam com preços não muito flexíveis. Dessa forma, toda vez que houver elevação do preço de um alimento base como o milho ou a soja, terá equivalente valorização o alimento sucedâneo.

Acredita-se que a produção de rações para os organismos aquáticos dobre nos próximos 12 a 15 anos. Para tanto, serão necessários grandes volumes de alimentos protéicos para atender as necessidades dietária dessas espécies. É fundamental que se conheça o valor nutritivo desses alimentos concentrados de origem vegetal, uma vez que podem apresentar baixa disponibilidade de alguns nutrientes, como no caso dos minerais.

É necessário que se conheça muito bem o valor nutritivo dos alimentos concentrados que compõe formula das rações dos peixes. Tal conhecimento permite suprir os nutrientes deficitários ou ausentes, especialmente àqueles considerados limitantes ao crescimento animal, como aminoácidos e minerais, ou ainda, melhorar os processos de obtenção desses alimentos, de forma que as perdas nutritivas sejam minimizadas.

\section{Valor nutritivo dos alimentos concentrados}

A análise química é o ponto inicial para determinação do valor nutritivo de um alimento, ingrediente ou ração (Maynard e Loosly, 1966). Entretanto, Pezzato et al. (2004) destacaram que após a ingestão, a efetiva assimilação dos nutrientes depende da aptidão fisiológica do animal. Hepher (1988) destacou que a digestão do alimento é principalmente influenciada pelo tamanho das partículas alimentares, pela atividade das enzimas digestivas e pelo tempo de exposição do alimento ao sistema digestório.

O conhecimento do coeficiente de digestibilidade dos alimentos e dos nutrientes permite a formulação de rações que melhor atendam as exigências nutricionais, evitando tanto a sobrecarga fisiológica quanto a ambiental. Destacase, ainda, a possibilidade da utilização de diversos alimentos alternativos os quais permitem cada vez mais a aproximação do ótimo biológico ao ótimo econômico.

\section{Alimentos concentrados energéticos}

Os valores médios dos coeficientes de digestibilidade aparente (CDA\%) da matéria seca (MS), proteína bruta (PB) e da energia bruta (EB) obtidos para os alimentos energéticos, pela tilápia-do-nilo, estão apresentados na Tabela 1.

Os coeficientes de digestibilidade aparente (CDA) do milho, amido de milho, sorgo e, dos farelos de trigo e de arroz foram determinados com a tilápia-do-nilo com peso médio de $100 \mathrm{~g}$, por Pezzato et al. (2002). Concluíram estes autores que dentre os alimentos energéticos, o milho apresentou o melhor CDA, seguido do farelo de trigo e farelo de arroz. Furuya et al. (2001) determinaram com juvenis de tilápia-donilo $(25,24 \pm 3,88 \mathrm{~g})$, os CDA do milho e do farelo de trigo e, segundo estes autores, os alimentos de origem vegetal são eficientemente utilizados pela tilápia-do-nilo, apresentando o milho melhor CDA que o farelo de trigo. Nesse sentido, Gonçalves et al. (2005) em estudo com a tilápia-do-nilo (peso médio de $100 \mathrm{~g}$ ), avaliaram a ação da fitase na digestibilidade de alimentos de origem vegetal e, segundo estes autores, os melhores CDA foram encontrados para o milho e o farelo de arroz; sendo estes alimetos melhores que o farelo de trigo e o sorgo. Gonçalves et al. (2007) determinaram com atilápia-do-nilo, o CDA doamido de milho, milho, farelo de trigo e quirera de arroz. Concluíram que, dentre os alimentos energéticos, o milho apresentou maior CDA para a energia. Guimarães et al. (2008a) determinaram, com a tilápia-do-nilo, o CDA da proteína, energia, matéria seca e, dos aminoácidos de diferentes alimentos energéticos e concluíram que a quirera de arroz, o sorgo e o milho apresentam os maiores CDA da energia e 
Tabela 1 - Coeficiente de digestibilidade aparente (CDA\%) da matéria seca (MS), proteína bruta (PB) e da energia bruta (EB) de alimentos energéticos, pela a tilápia-do-nilo $(100,0 \%$ na matéria seca)

\begin{tabular}{|c|c|c|c|c|c|}
\hline \multirow[t]{2}{*}{ Alimento } & \multicolumn{3}{|c|}{ CDA $(\%)$} & \multirow[t]{2}{*}{ Autor } & \multirow[t]{2}{*}{ Peixe $(g)$} \\
\hline & MS & PB & EB & & \\
\hline & 55,52 & 91,66 & 83,94 & Pezzato et al. (2002) & $100 \mathrm{~g}$ \\
\hline & 78,07 & 87,12 & 82,63 & Furuya et al. (2001) & $25 \mathrm{~g}$ \\
\hline \multirow[t]{3}{*}{ Milho (fubá) } & 69,27 & 91,01 & 75,75 & Gonçalves et al. (2005) & $100 \mathrm{~g}$ \\
\hline & 79,30 & 89,76 & 86,15 & Gonçalves et al. (2007) & $100 \mathrm{~g}$ \\
\hline & 82,21 & 72,86 & 67,34 & Guimarães et al. (2008a) & $100 \mathrm{~g}$ \\
\hline \multirow[t]{4}{*}{ Amido de milho } & 48,66 & 91,99 & 69,28 & Pezzato et al. (2002) & $100 \mathrm{~g}$ \\
\hline & 91,73 & - & 66,28 & Gonçalves et al. (2007) & $100 \mathrm{~g}$ \\
\hline & 66,05 & 91,13 & 77,70 & Pezzato et al. (2002) & $100 \mathrm{~g}$ \\
\hline & 67,32 & 78,21 & 70,34 & Furuya et al. (2001) & $25 \mathrm{~g}$ \\
\hline \multirow[t]{4}{*}{ Farelo de trigo } & 68,10 & 88,54 & 71,57 & Gonçalves et al. (2005) & $100 \mathrm{~g}$ \\
\hline & 70,37 & 93,54 & 72,83 & Gonçalves et al. (2007) & $100 \mathrm{~g}$ \\
\hline & 45,88 & 66,04 & 48,94 & Guimarães et al. (2008a) & $100 \mathrm{~g}$ \\
\hline & 59,29 & 94,86 & 91,29 & Pezzato et al. (2002) & $100 \mathrm{~g}$ \\
\hline \multirow[t]{2}{*}{ Farelo de arroz } & 69,99 & 77,48 & 78,05 & Gonçalves et al. (2005) & $100 \mathrm{~g}$ \\
\hline & 55,59 & 66,88 & 57,58 & Guimarães et al. (2008a) & $100 \mathrm{~g}$ \\
\hline \multirow[t]{3}{*}{ Quirera de arroz } & 81,91 & 95,88 & 75,48 & Gonçalves et al. (2007) & $100 \mathrm{~g}$ \\
\hline & 96,45 & 63,01 & 95,34 & Guimarães et al. (2008a) & $100 \mathrm{~g}$ \\
\hline & 23,44 & 67,33 & 70,53 & Pezzato et al. (2002) & $100 \mathrm{~g}$ \\
\hline \multirow[t]{2}{*}{ Sorgo } & 87,29 & 56,77 & 82,37 & Guimarães et al. (2008a) & $100 \mathrm{~g}$ \\
\hline & 32,86 & 75,12 & 63,15 & Freire et al. (2006) & $100 \mathrm{~g}$ \\
\hline \multirow[t]{2}{*}{ Sorgo (sem tanino) } & 70,05 & 82,50 & 72,10 & Gonçalves et al. (2005) & $100 \mathrm{~g}$ \\
\hline & 50,68 & 87,87 & 70,06 & Freire et al. (2006) & $100 \mathrm{~g}$ \\
\hline
\end{tabular}

da matéria seca, destacando a quirera de arroz como o melhor alimento energético para essa espécie.

Com base nesses resultados, pode-se observar que os valores médios dos coeficientes de digestibilidade aparente (CDA) (Tabela 1) da matéria seca (MS), mostram que a quirera de arroz apresentou o melhor coeficiente de digestibilidade aparente. Observa-se que o milho e o amido de milho apresentaram semelhantes coeficientes de digestibilidade aparente (CDA) da MS, embora esses valores médios se mostrem ligeiramente inferiores ao apresentado para a quirera de arroz. Observa-se, que os CDA da MS foram semelhantes e menores que os CDA médios encontrados para o farelo de arroz, farelo de trigo e o sorgo sem tanino; enquanto o menor CDA da MS foi apresentado pelo sorgo alto tanino.

Os valores médios dos CDA encontrados para a proteína bruta (PB) (Tabela 1) mostram que os CDA da PB do milho, farelo de trigo e do sorgo sem tanino apresentaram-se semelhantes e melhores que os apresentados pelos demais alimentos energéticos. Pode-se observar que a quirera e o farelo de arroz também apresentaram semelhantes CDA da $\mathrm{PB}$, embora se apresentem ligeiramente inferiores aos CDA médios apresentados para o milho, farelo de trigo e sorgo sem tanino. Da mesma forma que o resultado encontrado para a MS, o CDA médio para a PB do sorgo alto tanino se mostrou inferior, se comparado com os CDA dos demais alimentos energéticos.
Os resultados médios dos CDA encontrados para a energia bruta (EB) (Tabela 1) mostram que a quirera de arroz apresentou o melhor CDA para a EB. Entretanto, o milho apresentou ótimo CDA para a EB, com valores médios próximos ao encontrado para a quirera de arroz. Pode-se observar que bons CDA para a EB, também foram encontrados para o farelo de arroz e para o sorgo (com e sem tanino).

Os valores médios dos coeficientes de digestibilidade aparente da matéria seca, proteína bruta e da energia bruta obtidos para os alimentos energéticos, pela tilápia-do-nilo (Tabela 1) mostram que o milho, a quirera o farelo de arroz se apresentam com os melhores coeficientes de digestibilidade. Pode-se observar que o farelo de trigo se mostra como alimento energético com valores digestíveis, ligeiramente menores que aqueles encontrados para o milho e o arroz, provavelmente por apresentar maior porcentagem de fibra. Observa-se, ainda, que o sorgo alto tanino é aquele, dentre os alimentos concentrados energéticos, com menores CDA. Isso pode ser atribuído a ação antinutricional do tanino, uma vez que o sorgo sem tanino se mostrou com valores digestíveis melhores que aqueles encontrados para o farelo de trigo e, ligeiramente inferiores aos CDA do milho e do arroz.

\section{Alimentos concentrados protéicos}

\section{Alimentos protéicos de origem animal}

Os valores médios dos coeficientes de digestibilidade 
aparente (CDA\%) da matéria seca (MS), proteína bruta (PB) e da energia bruta (EB) obtidos para os alimentos concentrados protéicos de origem animal, obtidos pela tilápia-do-nilo, estão apresentados na Tabela 2.

Os coeficientes de digestibilidade aparente (CDA) das farinhas de peixe, de carne, vísceras, sangue e de penas foram determinados, com a tilápia-do-nilo com peso médio de $100 \mathrm{~g}$, por Pezzato et al. (2002). Concluíram estes autores que dentre os alimentos protéicos de origem animal, destacou-se a farinha de vísceras, seguida da farinha de peixes, enquanto os piores CDA foram apresentados pela farinha de penas e pela farinha de sangue. Guimarães et al. (2008b) determinaram com a tilápia-do-nilo, os CDA da proteína de alimentos concentrados protéicos de origem animal e concluíram que a farinha de vísceras e a farinha de peixe apresentaram os maiores CDA, enquanto a farinha de carne e a farinha de penas apresentaram os menores CDA. Narváez-Solarte (2006) avaliou, com juvenis de tilápia-donilo com peso médio de $100 \mathrm{~g}$, as farinhas de sangue processadas em tambor (FST), a atomizada (FSA) e a fração celular do sangue (FCS). Concluíu esse autor que a alta temperatura e o tempo prolongado para a obtenção da FST afetam a estrutura protéica, resultando em piores CDA da proteína da farinha de sangue em testes in vivo e in vitro. A FSA e FCS são eficientemente utilizadas pela tilápia-donilo, sendo a FST a proteína com inferior valor biológico.

Com base nesses resultados, pode-se observar que os valores médios dos coeficientes de digestibilidade aparente (CDA) (Tabela 2) da matéria seca (MS), mostram que a farinha de vísceras, a farinha de sangue atomizada (FSA) e a fração celular do sangue (FCS) apresentam os melhores coeficientes de digestibilidade aparente da MS. Pode-se observar que a farinha de peixe apresentou razoável coeficiente de digestibilidade aparente para a MS, embora esse valor médio se mostre ligeiramente inferior ao da farinha de vísceras, foi maior que o apresentado pela farinha de carne e, bem superior que aqueles CDA médios encontrados para a MS da farinha de penas e a farinha de sangue seca em tambor (FST). Destaca-se que a farinha de penas e a farinha de sangue seca em tambor apresentaram CDA muito baixos para a MS.

Os valores médios dos CDA encontrados para a proteína bruta (PB) (Tabela 2) mostram que os CDA da PB das farinhas de vísceras, de peixe, de sangue atomizado e da fração celular do sangue apresentaram-se semelh antes e melhores que os apresentados pelos demais alimentos protéicos. Pode-se observar que a farinha de carne também apresentou bom CDA da PB, embora com CDA para a PB ligeiramente inferior às anteriores. Da mesma forma que $\mathrm{o}$ resultado encontrado para a MS, a farinha de penas e da farinha de sangue seca em tambor apresentaram CDA muito baixos para a PB.

Os resultados médios dos CDA encontrados para a energia bruta (EB) (Tabela 2) mostram que a farinha de peixe, a farinha de sangue atomizado e a fração celular do sangue apresentaram similares e maiores que as demais. Entretanto, a farinha de vísceras também tenha apresentado bom CDA para a EB. Pode-se observar que a farinha de carne, a farinha de penas e a farinha de sangue seca em tambor apresentaram CDA muito baixos para a EB,

Tabela 2 - Coeficiente de digestibilidade aparente (CDA\%) da matéria seca (MS), proteína bruta (PB) e da energia bruta (EB) de alimentos protéicos de origem animal, para a tilápia-do-nilo $(100,0 \%$ na matéria seca)

\begin{tabular}{|c|c|c|c|c|c|}
\hline \multirow[t]{2}{*}{ Alimento } & \multicolumn{3}{|c|}{ CDA $(\%)$} & \multirow[t]{2}{*}{ Autor } & \multirow[t]{2}{*}{ Peixe $(g)$} \\
\hline & MS & PB & EB & & \\
\hline \multirow{6}{*}{ Farinha de peixe } & 57,46 & 78,55 & 72,23 & Pezzato et al. (2002) & $100 \mathrm{~g}$ \\
\hline & 72,81 & 84,95 & 87,27 & Furuya et al. (2001) & $25 \mathrm{~g}$ \\
\hline & 82,60 & 82,59 & 95,29 & Gonçalves et al. (2007) & $100 \mathrm{~g}$ \\
\hline & - & 88,60 & - & Guimarães et al. (2008b) & $100 \mathrm{~g}$ \\
\hline & 85,14 & 91,35 & 93,40 & Quintero-Pinto (2008) & 25 a $500 \mathrm{~g}$ \\
\hline & 46,97 & 73,19 & 75,35 & Pezzato et al. (2002) & $100 \mathrm{~g}$ \\
\hline \multirow[t]{3}{*}{ Farinha de carne } & - & 78,44 & - & Guimarães et al. (2008b) & $100 \mathrm{~g}$ \\
\hline & 68,97 & 88,26 & 60,59 & Quintero-Pinto (2008) & 25 a $500 \mathrm{~g}$ \\
\hline & 73,87 & 87,24 & 69,60 & Pezzato et al. (2002) & $100 \mathrm{~g}$ \\
\hline \multirow[t]{2}{*}{ Farinha de vísceras } & - & 89,73 & - & Guimarães et al. (2008b) & $100 \mathrm{~g}$ \\
\hline & 87,38 & 92,08 & 90,30 & Quintero-Pinto (2008) & 25 a $500 \mathrm{~g}$ \\
\hline \multirow[t]{2}{*}{ Farinha de penas } & 37,39 & 29,12 & 61,10 & Pezzato et al. (2002) & $100 \mathrm{~g}$ \\
\hline & - & 78,52 & - & Guimarães et al. (2008b) & $100 \mathrm{~g}$ \\
\hline \multirow[t]{2}{*}{ Farinha de sangue (tambor) } & 53,30 & 50,69 & 62,86 & Pezzato et al. (2002) & $100 \mathrm{~g}$ \\
\hline & 53,21 & 44,07 & 53,10 & Narváez-Solarte (2006) & $100 \mathrm{~g}$ \\
\hline Farinha de sangue (atomizada) & 95,43 & 84,35 & 91,74 & Narváez-Solarte (2006) & $100 \mathrm{~g}$ \\
\hline Farinha de sangue (célula) & 98,00 & 94,36 & 93,12 & Narváez-Solarte (2006) & $100 \mathrm{~g}$ \\
\hline
\end{tabular}


repetindo os resultados de CDA encontrados com esses alimentos para a MS e PB.

Os resultados apresentados na Tabela 2 mostram que a farinha de vísceras e a farinha de peixe se apresentam foram os alimentos concentrados protéicos de origem animal, com os melhores coeficientes de digestibilidade aparente (CDA). Observa-se (Tabela 2) que a farinha de vísceras se apresenta com tendência de superior CDA que a farinha de peixe. Por outro lado, observa-se que a farinha de carne apresentou CDA um pouco inferior às farinhas de vísceras e de peixe, enquanto a farinha de penas apresentou CDA inferior à estes três alimentos de origem animal. Deve-se destacar que a farinha de sangue atomizada e a farinha de células sanguíneas, embora se mostrem com excelentes CDA, devem ser empregadas com restrição como alimento para essa espécie, em função de baixa palatabilidade. Dentre os alimentos protéicos de origem animal, a farinha de sangue seca em tambor se mostrou com o pior CDA.

\section{Alimentos protéicos de origem vegetal}

Os valores médios dos coeficientes de digestibilidade aparente (CDA\%) da matéria seca (MS), proteína bruta (PB) e da energia bruta (EB) obtidos para os alimentos concentrados protéicos de origem vegetal, obtidos pela tilápia-do-nilo, estão apresentados na Tabela 3.

Furuya et al. (2001) utilizaram determinaram, com juvenis de tilápia-do-nilo $(25,24 \pm 3,88 \mathrm{~g})$, os coeficientes de digestibilidade aparente do farelo de soja e concluíram que a soja é eficientemente utilizada e apresentando ótimo
CDA. Pezzato et al. (2002) determinaram o CDA do glúten21, glúten-60, do farelos de soja, canóla e de algodão. Conclu íram estes autores que dentre os alimentos protéicos de origem vegetal, apresentaram os melhores CDA o glúten60 e o glúten-21, seguidos do farelo de canóla. Gonçalves et al. (2005) em estudo com a tilápia-do-nilo (peso médio de $100 \mathrm{~g}$ ), avaliaram a ação da fitase na digestibilidade de alimentos e concluíram o melhor CDA foi apresentado pelo farelo de soja, seguido pelo farelo de algodão-28, farelo de girassol e glúten de milho. Gonçalves et al. (2007) determinaram com a tilápia-do-nilo o CDA dos farelos de soja e de algodão e, do glúten de milho. Segundo estes autores, o farelo de soja se destacou com o maior CDA, superior ao do glúten de milho e farelo de algodão, os quais se mostraram com CDA superiores ao da farinha de peixe. Guimarães et al. (2008b) determinaram com essa mesma espécie, os CDA da proteína e dos aminoácidos do farelo de soja, farelo de algodão-28, farelo de algodão-38 e, do glúten-60 e concluíram que o glúten-60 e o farelo de soja apresentaram os maiores CDA, enquanto o farelo de algodão-28, o menor CDA.

Com base nesses resultados, pode-se observar que os valores médios dos coeficientes de digestibilidade aparente (CDA) (Tabela 3) da matéria seca (MS), mostram que o glúten-60, glúten-21 e o farelo de algodão-32 apresentam com médias semelhantes, os melhores coeficientes de digestibilidade aparente da MS. Pode-se observar que o farelo de soja apresentou razoável coeficiente de digestibilidade aparente para a MS, embora esse valor

Tabela 3 - Coeficiente de digestibilidade aparente (CDA\%) da matéria seca (MS), proteína bruta (PB) e da energia bruta (EB) de alimentos protéicos de origem vegetal, para tilápia-do-nilo (100,0\% na matéria seca)

\begin{tabular}{|c|c|c|c|c|c|}
\hline \multirow[t]{2}{*}{ Alimento } & \multicolumn{3}{|c|}{ CDA $(\%)$} & \multirow[t]{2}{*}{ Autor } & \multirow[t]{2}{*}{ Peixe (g) } \\
\hline & MS & $\mathrm{PB}$ & EB & & \\
\hline \multirow{6}{*}{ Farelo de soja } & 71,04 & 91,56 & 73,17 & Pezzato et al. (2002) & $100 \mathrm{~g}$ \\
\hline & 76,81 & 92,72 & 77,23 & Furuya et al. (2001) & $25 \mathrm{~g}$ \\
\hline & 68,70 & 91,31 & 75,60 & Gonçalves et al. (2005) & $100 \mathrm{~g}$ \\
\hline & 85,30 & 94,13 & 84,12 & Gonçalves et al. (2007) & $100 \mathrm{~g}$ \\
\hline & - & 92,44 & - & Guimarães et al. (2008b) & $100 \mathrm{~g}$ \\
\hline & 72,16 & 94,02 & 68,22 & Quintero-Pinto (2008) & 25 a $500 \mathrm{~g}$ \\
\hline \multirow[t]{3}{*}{ Glúten - 21} & 48,84 & 89,88 & 66,79 & Pezzato et al. (2002) & $100 \mathrm{~g}$ \\
\hline & 91,96 & 95,96 & 71,19 & Pezzato et al. (2002) & $100 \mathrm{~g}$ \\
\hline & 70,02 & 51,54 & 71,14 & Gonçalves et al. (2005) & $100 \mathrm{~g}$ \\
\hline \multirow[t]{4}{*}{ Glúten - 60} & 74,87 & 89,82 & 73,08 & Gonçalves et al. (2007) & $100 \mathrm{~g}$ \\
\hline & - & 91,39 & - & Guimarães et al. (2008b) & $100 \mathrm{~g}$ \\
\hline & 84,66 & 95,36 & 82,45 & Quintero-Pinto (2008) & 25 a $500 \mathrm{~g}$ \\
\hline & 53,11 & 74,87 & 51,00 & Pezzato et al. (2002) & $100 \mathrm{~g}$ \\
\hline \multirow[t]{3}{*}{ Farelo de algodão - 28} & 74,90 & 89,75 & 74,16 & Gonçalves et al. (2005) & $100 \mathrm{~g}$ \\
\hline & - & 78,59 & - & Guimarães et al. (2008b) & $100 \mathrm{~g}$ \\
\hline & 78,10 & 87,10 & 62,09 & Gonçalves et al. (2007) & $100 \mathrm{~g}$ \\
\hline \multirow[t]{2}{*}{ Farelo de algodão - 32} & - & 81,78 & - & Guimarães et al. (2008b) & $100 \mathrm{~g}$ \\
\hline & 85,73 & 92,59 & 88,74 & Quintero-Pinto (2008) & 25 a $500 \mathrm{~g}$ \\
\hline Farelo de canola & 66,38 & 87,00 & 74,59 & Pezzato et al. (2002) & $100 \mathrm{~g}$ \\
\hline Farelo de girassol & 66,64 & 89,05 & 75,72 & Gonçalves et al. (2005) & $100 \mathrm{~g}$ \\
\hline
\end{tabular}


médio se mostre ligeiramente inferior ao do glúten-60, glúten21 e do farelo de algodão-32. O glúten-21, farelo de algodão28 e os farelos de girassol e de canóla apresentaram CDA para a MS, semelhantes e inferiores aos encontrados com os demais concentrados protéicos de origem vegetal.

Os valores médios dos CDA encontrados para a proteína bruta (PB) (Tabela 3 ) mostram que os CDA da PB do farelo de soja apresentaram-se melhores que os apresentados pelos demais alimentos protéicos. Pode-se observar que o glúten-60, glúten-21, farelo de algodão-32, farelo de algodão-28, farelo de canóla e farelo de girassol também apresentaram ótimos e semelhantes CDA da PB.

Os resultados médios dos CDA encontrados para a energia bruta (EB) (Tabela 3) mostram que o farelo de soja, glúten-60, farelo de algodão-32, farelo de canóla e farelo de girassol apresentaram-se os melhores e semelhantes. Podese observar que o glúten-21 e o farelo de algodão-28 apresentaram os menores CDA para a EB, se comparados aos demais concentrados protéicos de origem vegetal.

Coeficientes de digestibilidade dos aminoácidos dos alimentos energéticos

Os valores médios dos coeficientes de digestibilidade aparente dos aminoácidos (CDAaa) obtidos para os alimentos concentrados energéticos, obtidos pela tilápiado-nilo, estão apresentados na Tabela 4.

O coeficiente de digestibilidade aparente dos aminoácidos (CDAaa) para esses seis alimentos energéticos (milho, farelo de trigo, quirera de arroz, farelo de arroz e sorgo), com a tilápia-do-nilo, estão apresentados na Tabela 4. A digestibilidade média dos aminoácidos foi maior para o milho (70,05\%), enquanto as mais baixas disponibilidades da metionina e da cistina foram apresentadas pelo farelo de trigo e farelo de arroz, respectivamente. A quirera de arroz mostrou-se o melhor alimento energético para a tilápia-do-nilo.

Observa-se que a digestibilidade aparente dos aminoácidos (CDAaa) dos alimentos energéticos, mostrouse variável entre os ingredientes e dentro de cada ingrediente. A digestibilidade média de todos os aminoácidos foi baixa, apresentando-se entre 59,50 e 70,05\% para o farelo de arroz e o milho, respectivamente. Com exceção do milho, o CDA da arginina foi alta para todos os alimentos (Tabela 4). O aminoácido histidina apresentou maiores valores de DA somente para o milho e a quirera de arroz, enquanto a leucina mostrou-se mais disponível para o milho e o sorgo.

A quirera de arroz apresentou os maiores valores de DA dos aminoácidos, embora não tenha diferido do farelo de trigo. O farelo de arroz apresentou maior digestibilidade para a tirosina. Destaca-se, ainda, o alto

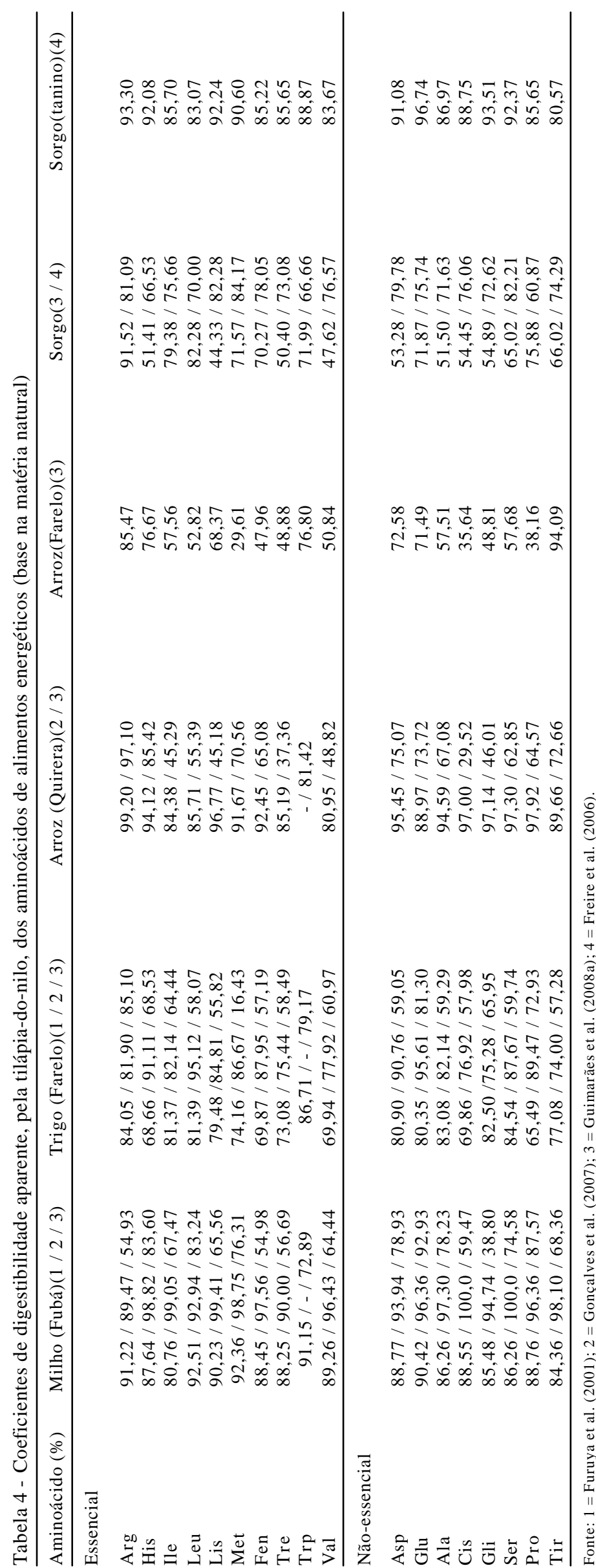

(C) 2009 Sociedade Brasileira de Zootecnia 
CDA do ácido glutâmico no farelo de trigo e no milho, e da prolina apenas para o milho. O milho apresentou, ainda, o maior valor de disponibilidade para a valina, alanina, metionina e serina, embora estes valores tenham se mostrado inferiores a $80,0 \%$.

O sorgo apresentou maior CDA do aminoácido isoleucina, se comparado aos demais alimentos. Já o farelo de trigo apresentou maior disponibilidade da glicina, enquanto o farelo de arroz a maior disponibilidade para a tirosina. O aminoácido metionina apresentou menor disponibilidade no farelo de trigo, seguido do farelo de arroz, enquanto a cistina apresentou baixa disponibilidade para a quirera de arroz.

Coeficientes de digestibilidade dos aminoácidos dos alimentos protéicos

Os valores médios dos coeficientes de digestibilidade aparente dos aminoácidos (CDAaa) obtidos para os alimentos concentrados protéicos de origem animal e de origem vegetal, obtidos pela tilápia-do-nilo, estão apresentados na Tabela 5 e 6 , respectivamente.

São escassos os valores de disponibilidade de aminoácidos dos alimentos para a tilápia-do-nilo, apesar de ser uma das espécies mais cultivadas mundialmente. Podese constatar que o coeficiente de digestibilidade aparente médio dos aminoácidos (CDAaa) da farinha de peixe, farinha de carne, farinha de vísceras, farinha de penas, farinha de sangue seca em tambor, farinha de sangue atomizada, da fração celular do sangue, do farelo de soja, glúten-60, farelo de algodão-32, farelo de algodão-28 se mostra similar ao valor obtido para a digestibilidade da proteína.

Desta forma, a digestibilidade da proteína pode ser em parte, usada para estimar a disponibilidade média dos aminoácidos do alimento. Pode-se observar que os coeficientes de digestibilidade aparente (CDA) da proteína e dos aminoácidos, dos diferentes alimentos (Tabelas 5 e 6 ) mostram diferenças significativas entre os alimentos, quanto a digestibilidade da proteína e a digestibilidade dos diferentes aminoácidos.

Entre os alimentos protéicos de origem vegetal, o farelo de soja foi o alimento que apresentou maior coeficiente de digestibilidade aparente para os aminoácidos arginina, lisina, triptofano e valina. Entretanto, para os demais aminoácidos essenciais não foi observada diferença entre o farelo de soja e o glúten de milho. Os menores valores de CDAaa foram para o farelo de algodão-28 e farelo de algodão-38, respectivamente.

Para os alimentos protéicos de origem animal, a farinha de vísceras de aves foi o que apresentou maior CDAaa para os aminoácidos histidina, fenilalanina e metionina.

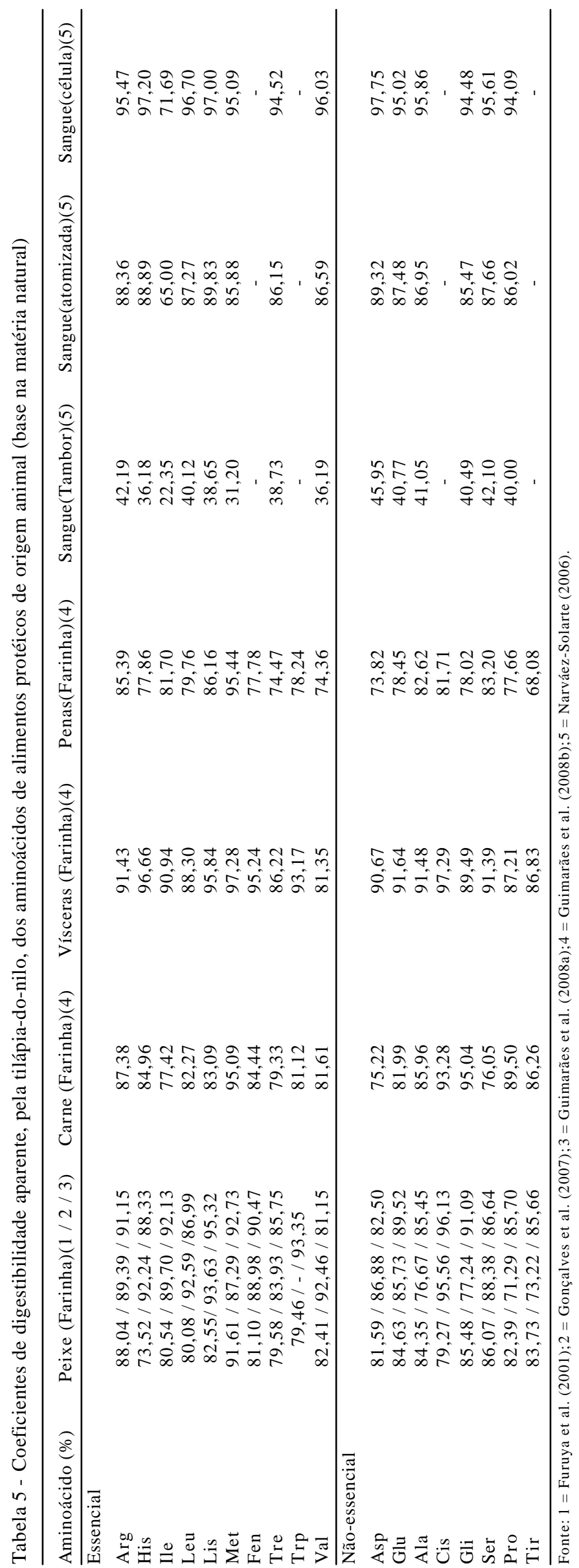

(c) 2009 Sociedade Brasileira de Zootecnia 
Tabela 6 - Coeficientes de digestibilidade aparente, pela tilápia-do-nilo, dos aminoácidos de alimentos protéicos de origem vegetal (base na matéria natural)

\begin{tabular}{|c|c|c|c|c|}
\hline Aminoácido (\%) & Soja (Farelo)(1 / $2 / 3)$ & Glúten-60 (Farelo)(2 / 3) & Algodão-28 (Farelo)(2 / 3) & Algodão-32 (Farelo)(3) \\
\hline \multicolumn{5}{|l|}{ Essencial } \\
\hline Arg & $96,21 / 94,53 / 94,57$ & $90,48 / 90,16$ & $76,06 / 47,99$ & 89,55 \\
\hline His & $92,41 / 94,4094,36$ & $100,0 / 91,06$ & $71,56 / 62,77$ & 81,74 \\
\hline Ile & $87,48 / 92,64 / 91,24$ & $79,53 / 89,16$ & $66,41 / 80,63$ & 86,02 \\
\hline Leu & $91,04 / 93,32 / 91,53$ & $84,37 / 92,92$ & $71,31 / 86,77$ & 80,68 \\
\hline Lis & $90,83 / 97,01 / 96,64$ & $86,54 / 91,23$ & $83,14 / 74,24$ & 69,03 \\
\hline Met & $97,10 / 90,70 / 93,45$ & $94,96 / 95,92$ & $95,83 / 94,26$ & 81,47 \\
\hline Fen & $93,33 / 97,58 / 94,28$ & $89,92 / 91,69$ & $80,19 / 80,08$ & 70,23 \\
\hline Tre & $90,29 / 90,40 / 87,07$ & $80,63 / 85,58$ & $75,00 / 52,71$ & 74,28 \\
\hline Trp & $92,61 /-/ 97,82$ & $-/ 90,22$ & $-/ 78,73$ & 87,68 \\
\hline Val & $89,38 / 90,00 / 89,82$ & $81,1284,84$ & $66,49 / 63,08$ & 80,83 \\
\hline \multicolumn{5}{|l|}{ Não-essencial } \\
\hline Asp & $93,93 / 92,31 / 94,88$ & $94,00 / 87,07$ & $77,89 / 67,26$ & 83,50 \\
\hline Glu & $95,97 / 94,34 / 96,23$ & $91,79 / 94,45$ & $77,07 / 85,29$ & 89,54 \\
\hline Ala & $87,21 / 90,77 / 84,24$ & $97,02 / 90,36$ & $77,16 / 81,71$ & 73,60 \\
\hline Cis & $93,97 / 92,68 / 89,30$ & $98,39 / 84,67$ & $80,00 / 82,94$ & 87,87 \\
\hline Gli & $87,08 / 81,05 / 88,38$ & $78,38 / 80,53$ & $69,23 / 52,21$ & 76,68 \\
\hline Ser & $97,03 / 99,0890,68$ & $98,30 / 90,76$ & $73,08 / 79,22$ & 79,12 \\
\hline Pro & $87,39 / 89,17 / 89,60$ & $65,56 / 93,92$ & $79,74 / 57,78$ & 77,42 \\
\hline Tir & $88,84 / 82,86 / 97,77$ & $84,69 / 87,63$ & $96,77 / 94,58$ & 83,65 \\
\hline
\end{tabular}

Fonte: 1 = Furuya et al. (2001);2 = Gonçalves et al. (2007); 3 = Guimarães et al. (2008b).

Entretanto, para os demais aminoácidos não foi observada diferença entre este alimento e a farinha de peixe, apesar da farinha de vísceras de aves ter mostrado tendência de maiores valores. Observa-se, ainda, que a fração celular do sangue bovino atomizado e a fração celular de sangue bovino são eficientemente utilizados pela tilápia-do-nilo.

Entre os alimentos protéicos de origem animal, a farinha de penas, farinha de carne e a farinha de sangue seca em tambor foram aqueles que revelaram os menores valores de CDAaa., se mostram com proteína com de valor biológico inferior aos demais. Dentre os aminoácidos, deve ser considerada a isoleucina como primeiro limitante na formulação de dietas para a tilápia-do-nilo com o uso de farinha de sangue, seguida pela metionina+cistina, arginina e treonina, que foram encontradas em níveis limitantes para essa espécie, principalmente na farinha de sangue seca em tambor.

Todos os alimentos protéicos (vegetal e animal), exceto os farelos de algodão 28 e 32, apresentaram CDA maiores que $70,0 \%$. Os aminoácidos que se apresentaram com CDA menores que $70,0 \%$, nesses alimentos, foram a treonina, valina, ácido aspártico, glicina e a prolina para o farelo de algodão-28 e, a lisina para o farelo de algodão-32.

\section{Considerações Finais}

O valor nutritivo de um alimento não pode ser norteado apenas por seu conteúdo em proteína bruta. A proteína bruta não deve ser considerada isoladamente sem que se conheçam os coeficientes de digestibilidade e os balanços dos aminoácidos que constituem essa proteína. Didaticamente ela reflete o valor nutritivo médio da proteína de cada um desses concentrados. Para os peixes tropicais e, especialmente para as espécies onívoras, o farelo de soja deve ser considerado o "alimento protéico padrão" para formulação das rações.

Entretanto, o preço dos concentrados protéicos sempre será problema para a piscicultura e são poucas as informações sobre o valor nutritivo dos alimentos com potencial para as dietas das espécies tropicais cultivadas. Isso ganha importância ao se considerar o preço dos alimentos energéticos e, especialmente os protéicos.

As espécies de peixes, principalmente as cultivadas em nosso país são onívoras, as quais podem ser consideradas ecologicamente e economicamente mais viáveis que aquelas produzidas com rações à base de produtos de origem animal. Entretanto, o Brasil é um dos maiores produtores de subprodutos de abatedouro de aves e de bovinos do mundo, aliás, alimentos protéicos que podem ser equiparados à farinha de peixe.

\section{Literatura Citada}

FURUYA, W.M.; PEZZATO, L.E.; PEZZATO, A.C. et al. Coeficiente de digestibilidade e valores de aminoácidos digestíveis de alguns ingredientes para a tilápia do Nilo (Oreochromis niloticus). Revista Brasileira de Zootecnia, v.30, n.4, p.1143-1149, 2001.

GONÇALVES, G.S.; PEZZATO, L.E.; BARROS, M.M. et al. Efeito da suplementação de fitase sobre a disponibilidade aparente de 
nutrientes em alimentos vegetais pela tilápia do Nilo (Oreochromis niloticus). Revista Brasileira de Zootecnia, v.34, n.6, p.2155-2163, 2005.

GONÇAlVES, G.S.; PEZZATO, L.E.; PADILHA, P.M. et al. Digestibilidade aparente de fósforo em alimentos vegetais e suplementação da enzima fitase para tilápia do Nilo (Oreochromis niloticus). Revista Brasileira de Zootecnia, v.36, p.1473-1480, 2007.

GUIMARÃES, I.G.; PEZZATO, L.E.; BARROS, M.M. et al. Nutrient digestibility of several grain products and by-products in extruded diets for Nile tilapia, Oreochromis niloticus. Journal of the Aquaculture Society, v.39, p.781-789, 2008a.

GUIMARÃES, I.G.; PEZZATO, L.E.; BARROS, M.M. et al. Amino acid availability and protein digestibility of several protein sources for Nile tilapia, Oreochromis niloticus. Aquaculture Nutrition, v.14, p.396-404, 2008b.

HEPHER, B. Nutrition of pond fishes. New York: Cambridge University Press, 1988. 388p.

MAYNARD, L.A; LOOSLY, J.K. Nutrição animal. Rio de Janeiro: McGraw Hill, 1966. 550p.
NARVÁEZ-SOLARTE, W.V. Avaliação nutricional de farinhas de sangue como alimento para a tilápia do Nilo (Oreochromis niloticus). 2006. Tese de Doutorado, Faculdade de Medicina Veterinária e Zootecnia, Universidade Estadual Paulista, Botucatu, Brasil.

PEZZATO, L.E.; BARROS, M.M., FRACALOSSI, D.M., CYRINO, J.E.P. Nutrição de peixes. In: CYRINO, J.E.P.; URBINATI, E.C.; FRACALOSSI, D.M. (Eds.) Tópicos especiais em piscicultura de água doce tropical intensiva. São Paulo: TecArt, 2004. p.75-169.

PEZZATO, L.E.; MIRANDA, E.C.; BARROS, M.M. et al. Digestibilidade aparente de ingredientes pela tilápia do Nilo (Oreochromis niloticus). Revista Brasileira de Zootecnia, v.31, p.1595-1604, 2002.

QUINTERO-PINTO, L.G. Digestibilidade aparente de nutrientes e disponibilidade de fósfatos inorgânicos, pela tilápia do Nilo (Oreochromis niloticus) em três fases de desenvolvimento. 2008. Tese de Doutorado, Faculdade de Medicina Veterinária e Zootecnia, Universidade Estadual Paulista, Botucatu, 2008. 